Leah Zallman, MD, MPH*; Wayne Altman, MD, FAAFP; Sharon Touw, $\mathrm{MPH}$; Lendy Chu, MPH; Megan Hatch, MPH; Karissa Rajagopal, BS; David Elvin, MD; Steven Dolat, MBA; Assaad Sayah, MD

Institute for Community Health, Malden, MA (Dr. Zallman, Ms. Touw, and Ms. Chu); Cambridge Health Alliance, MA (Drs. Zallman, Elvin, and Sayah and Mr. Dolat); Harvard Medical School, Boston (Drs. Zallman, Elvin, and Sayah); Tufts University School of Medicine, Boston (Dr. Altman); Massachusetts General Hospital, Boston (Ms. Hatch); University of New England, Biddeford, ME (Ms. Rajagopal)

*Deceased.

\#wayne.altman@tufts.edu

The authors reported no potential conflict of interest relevant to this article. This study was funded by institutional funds of the Cambridge Health Alliance and the Department of Family Medicine at Tufts University School of Medicine.

doi: 10.12788/jfp.0185

ORIGINAL RESEARCH

\title{
The financial advantages of medical scribes extend beyond increased visits
}

\author{
Employing medical scribes can boost revenue for \\ a practice, the authors show, well beyond being an \\ opportunity to expand patient volume.
}

\section{ABSTRACT}

Purpose Medical scribes are known to increase revenue by increasing visits to a medical practice. We examined whether medical scribes are associated with markers of financial benefit independent of increased visits.

-Methods We conducted a pre- and postobservational study with a control group, examining changes in the percentage of visits (1) coded as level of service 4 or 5, (2) with at least 1 hierarchical condition category code billed, and (3) at which orders for 3 pay-forperformance quality measures (screening for breast, cervical, and colon cancer) were placed, if due. We looked at changes in outcomes among scribed providers and compared them to nonscribed providers. We used generalized estimating equations with robust standard errors to account for repeated measures and the hierarchical nature of the data, controlling for patient demographics.

-Results We examined 41,371 visits to 17 scribed providers and 230,297 visits to 78 nonscribed providers. In adjusted analyses, and compared to nonscribed providers, scribes were associated with an increase of:

- 9.2 percentage points in level-of-service 4 or 5 billing $(P<.001)$

- 3.6 percentage points in hierarchical condition category coding $(P<.001)$

- 4.0 percentage points in breast cancer screening orders $(P=.01)$

- 4.9 percentage points in colon cancer screening orders $(P=.04)$.

Conclusions This study suggests that scribes are associated with financial benefit in addition to increased visit volume. Primary care practices should consider the financial benefit of scribes independent of their ability to add patient volume.

I ncreasingly, medical scribes are used in ambulatory care settings across the United States. ${ }^{1}$ Scribes are trained personnel who accompany providers during visits to provide documentation support and assist with other administrative tasks. They are associated with reduced documentation time for providers ${ }^{2-6}$ and improved provider satisfaction, ${ }^{7-11}$ without detriment to ${ }^{4-16}$ (or with possible improvement in ${ }^{17-20}$ ) patient satisfaction in ambulatory care settings. At the same time, concerns remain that using scribes might inhibit patient communication, harm clinical reasoning, reduce the effectiveness of clinical decision-support tools, and simply serve as a work-around to fixing inefficiencies in the electronic medical record (EMR)..$^{21-23}$

A driving force for the increased use of medical scribes is the expectation that they reduce the cost of providing care. Costefficiency is typically described as resulting 
from a reduction in physician time per patient seen, which allows increased patient volume and, in turn, drives increased physician productivity. ${ }^{2,8,10,18,24-27}$ Whether scribes result in cost savings remains unclear; some papers suggest that scribes are cost efficient in ambulatory care, ${ }^{2,10,18}$ while others have been unable to identify cost savings, particularly in primary care. ${ }^{4}$

One reason why scribes might not be associated with cost savings is that their financial benefit might be undercounted. Studies that focus on increased volume miss the opportunity to capture financial benefits conferred through mechanisms that are independent of seeing more patients:

- Scribes might help providers address and document more, and more complex, medical problems, allowing higher levelof-service (LOS) billing. For example, a provider chooses a lower LOS because they have insufficiently documented a visit to support a higher LOS; by assisting with documentation, the scribe might allow the provider to choose a higher LOS.

- Scribes might prompt a provider to use decision-support tools for risk coding (using appropriate medical codes to capture the patient's level of medical complexity), thereby increasing reimbursement.

- Scribes might extend the time available during the visit for the provider to address pay-for-performance quality measures, such as cancer screening.

I Making visits count, not counting visits. In this study, we examined whether medical scribes in primary care are associated with improved markers of revenue that are independent of seeing more patients. Specifically, we examined whether scribes are associated with increased LOS coding, risk coding, and orders for pay-for-performance measures for all primary care visits and for nonpreventive primary care visits.

\section{Methods \\ Design}

This observational study compared the change in outcomes before implementation of scribes and during implementation of scribes, between scribed providers and nonscribed providers. We compared visits during the year prior to the implementation of scribes (July 2017-June 2018) with the year during their implementation (July 2018-2019).

The Cambridge Health Alliance Institutional Review Board considered this study exempt from review.

\section{Setting}

This study was conducted at a safety-net community academic health system that uses an EMR developed by Epic Systems [Verona, WI]. This EMR includes decision-support tools that prompt providers when pay-forperformance quality measures are due and when hierarchical condition category (HCC) codes-ie, specific diagnoses used by Medicare and other payers to reimburse providers for the complexity of their patients-might apply to the visit.

These EMR decision-support tools use algorithms that draw on age, gender, diagnoses that were billed previously or are on the problem list, laboratory findings, and prior imaging. They alert physicians when a patient is due for pay-for-performance quality measures, such as cancer screenings, and when HCC codes might be applicable.

During the study period, the EMR decision-support tool for HCC coding underwent several changes designed to improve HCC coding. In addition, systematic changes to primary care visits took place, leading to an increase in the number of patients seen and screenings required.

\section{Outcomes}

We examined 2 categories of outcomes that confer financial benefit to many institutions: billing measures and pay-for-performance measures.

- Billing measures included the percentage of visits (1) coded as LOS 4 or 5 and (2) with at least 1 HCC code billed (among those for which the decision-support tool identified at least 1 potential HCC code).

- Pay-for-performance measures. We examined whether any of 3 pay-forperformance quality measures were addressed during the visit, selecting 3 that are

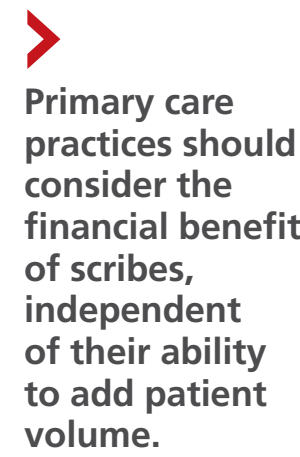

volume. 


\section{$>$}

\section{Scribes might extend the time available during the visit for the provider to address pay-for- performance quality measures, such as cancer screening.}

commonly addressed by primary care providers (PCPs) and that require PCPs to sign an order for screening during a primary care visit: breast cancer (mammography order), cervical cancer (Papanicolaou smear order), and colon cancer (an order for fecal occult blood testing or colonoscopy).

\section{Intervention}

Scribes were employees of Cambridge Health Alliance who had recently graduated from college and were interested in a career as a health care professional. Scribes received 3 days of training on how to function effectively in their role; 1 day of training in EMR functionality; and 2 hours of training on decision-support tools for pay-for-performance quality measures and risk coding. Scribes continued learning on the job through feedback from supervising PCPs. Scribes documented patient encounters, recording histories and findings on the physical exam and transcribing discussion of treatment plans and the PCP's instructions to patients.

The 14 scribes worked with 17 physician and nurse practitioner PCPs beginning in July 2018. Participation by PCPs was voluntary; they received no compensation for participating in the scribe program. PCPs were not required to see additional patients to participate. PCPs who chose to work with a scribe were similar to those who declined a scribe, as regards gender, race, type of provider (MD or NP), tenure at the institution, and percentage of time in clinical work (see TABLE $\mathbf{w}$-1 at www.mdedge.com/familymedicine).

The control group comprised providers who elected not to work with a scribe but who worked in the same clinics as the intervention providers.

Scribes were assigned to a PCP based on availability during the PCP's scheduled hours and worked with 1 PCP throughout the intervention (except for 1 PCP who worked with 2 scribes). All PCPs worked with their scribe(s) part time; on average, $49 \%$ of intervention PCPs' visits were scribed.

\section{Inclusion and exclusion criteria}

Because the first year at an institution is a learning period for PCPs, we excluded those who worked at the institution for $<1$ year be- fore the start of the scribe program $(n=12)$. Based on the extensive clinical experience of 1 PCP (WA) with scribes, we excluded the first 200 visits or 6 weeks (whichever occurred first) with a scribe among all scribed providers, to account for an initial learning period ( $n=2202$, of 15,372 scribed visits [14\%]). We also excluded 2 providers who left during the pre-intervention period or were in the intervention period for $<1$ month.

To ensure that we captured visits to providers with clinically significant exposure to scribes, we required scribed providers to have $\geq 20 \%$ of their visits scribed during the intervention period. To minimize the potential for contamination, we excluded nonscribed visits to scribed providers during the intervention period $(n=2211)$, because such nonscribed visits were largely due to visits outside the scribe's scheduled time.

\section{Analysis}

We compared demographic characteristics for patients and providers using the chisquare test for categorical variables and the $t$ test for continuous variables. We compared the change in outcomes from before implementation of scribes to during implementation of scribes among scribed providers, compared to nonscribed providers, using generalized estimating equations with robust standard errors to account for repeated measures (ie, multiple visits by the same patients) and the hierarchical nature of the data (ie, patients nested within providers). We then recalculated these estimates, controlling for patient demographics (age, gender, race, and ethnicity). We repeated these analyses for patients presenting for nonpreventive visits.

\section{Results}

\section{Visit characteristics}

We examined 271,768 visits, including 41,371 visits to 17 scribed providers and 230,397 visits to 78 nonscribed providers (TABLE 1). Patients were most likely to be female, $>21$ years of age, have English as their language of care, and be non-White. Most visits were by established patients and were nonpreventive.

We noted no clinically significant differences in characteristics between visits with 
TABLE 1

Patient and visit characteristics of visits to scribed and nonscribed providers, before and during implementation of scribes

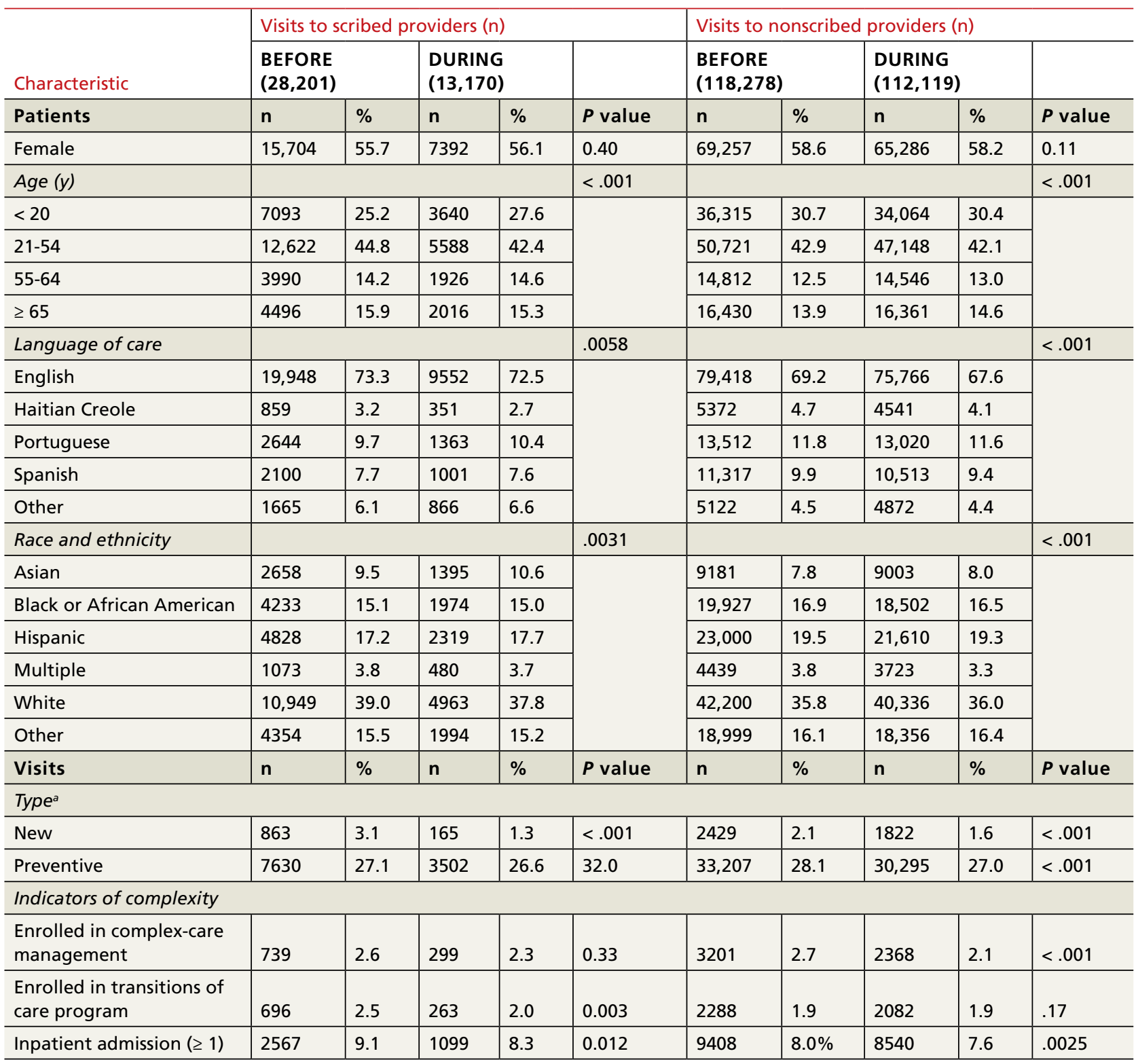

a New patient visits are defined by Current Procedural Terminology Codes 99201-99204. Preventive visits are defined by Current Procedural Terminology Codes 99381-7, 99391-7, G0438, or G0439. These are not mutually exclusive categories.

scribed providers and visits with nonscribed providers, and over time. Patient complexity measures, including care management enrollment and hospital admissions, were also similar between groups, and over time.

\section{Billing measures}

HCC coding. In $28.6 \%$ of visits, the decision- support tool identified at least 1 potential HCC code. Among these, the percentage of visits with at least 1 HCC code billed increased by 10.1 percentage points (from $3.9 \%$ before implementation of scribes to $14.0 \%$ ) among scribed providers, compared to increasing by 6.5 percentage points (from $2.9 \%$ before implementation to $9.3 \%$ ) 
TABLE 2

Changes in markers of revenue for visits to scribed and nonscribed providers, before and during implementation of scribes

\begin{tabular}{|c|c|c|c|c|c|c|c|c|c|c|}
\hline & \multicolumn{4}{|c|}{ Billing measures $(n)$} & \multicolumn{6}{|c|}{$\begin{array}{l}\text { Pay-for-performance quality measures } \\
\text { in cancer screening ( } n \text { ) }\end{array}$} \\
\hline & \multicolumn{2}{|c|}{$\begin{array}{l}\text { Hierarchical } \\
\text { condition } \\
\text { category coding } \\
(77,630)\end{array}$} & \multicolumn{2}{|c|}{$\begin{array}{l}\text { Level of service } \\
4 \text { or } 5 \\
(206,930)\end{array}$} & \multicolumn{2}{|c|}{$\begin{array}{l}\text { Breast } \\
(23,245)\end{array}$} & \multicolumn{2}{|c|}{$\begin{array}{l}\text { Cervical } \\
(17,922)\end{array}$} & \multicolumn{2}{|c|}{$\begin{array}{l}\text { Colon } \\
(8,984)\end{array}$} \\
\hline & $\mathbf{n}$ & $\%$ & $\mathbf{n}$ & $\%$ & $\mathbf{n}$ & $\%$ & $\mathbf{n}$ & $\%$ & $\mathbf{n}$ & $\%$ \\
\hline \multicolumn{11}{|c|}{ Visits to scribed providers } \\
\hline $\begin{array}{l}\text { Before } \\
\text { implementation } \\
(n=28,201)\end{array}$ & 331 & 3.9 & 10,295 & 47.3 & 2520 & 17.3 & 1862 & 31.4 & 918 & 19.2 \\
\hline $\begin{array}{l}\text { During } \\
\text { implementation } \\
(n=13,170)\end{array}$ & 540 & 14.0 & 5907 & 56.8 & 1224 & 20.0 & 856 & 31.4 & 482 & 20.3 \\
\hline Change $^{a}$ & & 10.1 & & 9.6 & & 2.7 & & - & & 1.2 \\
\hline \multicolumn{11}{|c|}{ Visits to nonscribed providers } \\
\hline $\begin{array}{l}\text { Before } \\
\text { implementation } \\
(n=118,278)\end{array}$ & 975 & 2.9 & 41,532 & 46.5 & 9874 & 19.5 & 7948 & 33.8 & 3561 & 18.5 \\
\hline $\begin{array}{l}\text { During } \\
\text { implementation } \\
(n=112,119)\end{array}$ & 2906 & 9.3 & 40,854 & 47.8 & 9627 & 17.6 & 7256 & 31.3 & 4037 & 15.9 \\
\hline Change $^{a}$ & & 6.5 & & 1.3 & & -1.9 & & -2.5 & & -2.7 \\
\hline \multicolumn{11}{|c|}{ Difference between scribed and nonscribed providers over time } \\
\hline & $\%$ & $P$ value & $\%$ & $P$ value & $\%$ & $P$ value & $\%$ & $P$ value & $\%$ & $P$ value \\
\hline Unadjusted & 3.6 & $<.0001$ & 8.3 & $<.001$ & 4.6 & .003 & 2.6 & .26 & 3.9 & .112 \\
\hline Adjusted $^{b}$ & 3.6 & $<.0001$ & 9.2 & $<.001$ & 4.0 & .01 & 2.3 & .31 & 4.9 & .044 \\
\hline
\end{tabular}

a In percentage points.

${ }^{b}$ Controlling for age, gender, race and ethnicity of patients, and repeated visits.

among nonscribed providers (TABLE 2). Scribes were therefore associated with an additional 3.6 percentage-point increase in visits with at least 1 HCC code billed $(P<.0001)-$ a difference that remained significant after adjusting for patient demographics $(P<.0001)$.

LOS coding. Scribed providers increased the number of visits billed as LOS 4 or 5 by 9.6 percentage points (from $47.3 \%$ before implementation to $56.8 \%$ ); during the same period, nonscribed providers increased the number of visits billed as LOS 4 or 5 by 1.3 percentage points (from $46.5 \%$ before implementation to $47.8 \%$ ) (TABLE 2). Scribes were therefore associated with an additional 8.3 percentage points in LOS 4 or 5 billing $(P<.001)$ (TABLE 2$)$. This difference remained significant after adjusting for patient demographics $(P<.001)$.

\section{Pay-for-performance quality measures}

- Breast cancer screening. Scribed providers increased the number of visits at which breast cancer screening was ordered by 2.7 percentage points (from $17.3 \%$ before implementation of scribes to $20.0 \%$ ); during the same period, the number of visits at which breast cancer screening was ordered by nonscribed providers decreased by 1.9 percentage points (from $19.5 \%$ to $17.6 \%$ ). Scribes were therefore associated with an increase of 4.6 percentage points in breast cancer screening orders, compared to nonscribed providers $(P<.003)$ (TABLE 2$)$. That difference remained significant after adjusting for patient demographics $(P=.01)$. 
TABLE 3

Changes in markers of revenue among nonpreventive visits to scribed and nonscribed providers, before and during implementation of scribes

\begin{tabular}{|c|c|c|c|c|c|c|c|c|c|c|}
\hline & \multicolumn{4}{|c|}{ Billing measures $(n)$} & \multicolumn{6}{|c|}{ Pay-for-performance quality measures in cancer screening (n) } \\
\hline & \multicolumn{2}{|c|}{$\begin{array}{l}\text { Hierarchical } \\
\text { condition } \\
\text { category coding } \\
(66,291)\end{array}$} & \multicolumn{2}{|c|}{$\begin{array}{l}\text { Level of service } \\
4 \text { or } 5 \\
(190,631)\end{array}$} & \multicolumn{2}{|c|}{$\begin{array}{l}\text { Breast } \\
(19,122)\end{array}$} & \multicolumn{2}{|c|}{$\begin{array}{l}\text { Cervical } \\
(12,919)\end{array}$} & \multicolumn{2}{|c|}{$\begin{array}{l}\text { Colon } \\
(7,760)\end{array}$} \\
\hline & $\mathbf{n}$ & $\%$ & $\mathbf{n}$ & $\%$ & $\mathbf{n}$ & $\%$ & $\mathbf{n}$ & $\%$ & $\mathbf{n}$ & $\%$ \\
\hline \multicolumn{11}{|c|}{ Visits to scribed providers } \\
\hline $\begin{array}{l}\text { Before } \\
\text { implementation } \\
(n=20,571)\end{array}$ & 256 & 3.5 & 9998 & 49.8 & 266 & 12.9 & 221 & 16.5 & 114 & 14.7 \\
\hline $\begin{array}{l}\text { During } \\
\text { implementation } \\
(n=9668)\end{array}$ & 445 & 13.3 & 5695 & 59.7 & 157 & 15.0 & 112 & 17.8 & 66 & 15.6 \\
\hline Change $^{a}$ & & 9.8 & & 9.9 & & 2.1 & & 1.4 & & 1.0 \\
\hline \multicolumn{11}{|c|}{ Visits to nonscribed providers } \\
\hline $\begin{array}{l}\text { Before } \\
\text { implementation } \\
(n=85,701)\end{array}$ & 744 & 2.6 & 39,079 & 47.6 & 1180 & 14.7 & 1026 & 18.1 & 431 & 14.2 \\
\hline $\begin{array}{l}\text { During } \\
\text { implementation } \\
(n=81,824)\end{array}$ & 2461 & 9.2 & 38,651 & 49.0 & 1087 & 13.6 & 954 & 18.0 & 431 & 12.2 \\
\hline Change $^{a}$ & & 6.7 & & 1.4 & & -1.2 & & -0.1 & & -2.0 \\
\hline \multicolumn{11}{|c|}{ Difference between scribed and nonscribed providers over time } \\
\hline & $\%$ & $P$ value & $\%$ & $P$ value & $\%$ & $P$ value & $\%$ & $P$ value & $\%$ & $P$ value \\
\hline Unadjusted & 3.1 & $<.001$ & 8.2 & $<.001$ & 3.2 & .03 & 1.5 & .48 & 3.1 & .19 \\
\hline Adjusted $^{\mathrm{b}}$ & 3.6 & $<.001$ & 9.4 & $<.001$ & 2.8 & .06 & 1.7 & .41 & 3.8 & .11 \\
\hline
\end{tabular}

a In percentage points.

${ }^{b}$ Controlling for age, gender, race, and ethnicity of patients, and repeated visits.

I Colon cancer screening. Similarly, scribed providers increased the number of visits at which colon cancer screening was ordered by 1.2 percentage points (from $19.2 \%$ before implementation of scribes to $20.3 \%$ ); during the same period, the number of visits at which colon cancer screening was ordered by nonscribed providers decreased by 2.7 percentage points (from $18.5 \%$ to $15.9 \%$ ) $(P=.112)$. After adjusting for patient demographics, scribes were associated with an increase of 4.9 percentage points in colon cancer screening orders, compared to nonscribed providers $(P=.044)$ (TABLE 2).

I Cervical cancer screening. The rate at which cervical cancer screening was ordered did not change among scribed providers and decreased (by 2.5 percentage points) among nonscribed providers-a difference that was not statistically significant $(P=.26)$.

I Nonpreventive visits. Our findings overall did not change in analyses focused on nonpreventive visits, in which scribes were associated with an increase of 8.2 percentage points in LOS 4 or 5 billing $(P<.001)$; an increase of 3.1 percentage points in HCC coding $(P<.001)$; and an increase of 3.2 percentage points in breast cancer screening orders $(P=.03)$ (TABLE 3). Although scribes were associated with an increase of 1.5 percentage points in cervical cancer screening orders and an increase of 3.1 percentage points in 
colon cancer screening orders, these increases did not reach statistical significance.

\section{Discussion}

We found that implementation of scribes is associated with (1) an increase in LOS coding and risk coding and (2) a higher frequency of addressing 2 of 3 pay-for-performance quality measures in primary care. In adjusted analyses in our study, and compared to nonscribed providers, scribes were associated with an additional 9.2 percentage points in LOS 4 or 5 billing; 3.6 percentage points in HCC coding; 4.0 percentage points in breast cancer screening orders; and 4.9 percentage points in colon cancer screening orders. Cervical cancer screening orders followed a similar pattern, with an increase of 2.3 percentage points in the adjusted screening order rate among scribed providers, compared to nonscribed providers, during implementation of scribes-although the increase was not significant. These findings did not change in analyses focused on nonpreventive visits.

I Our findings are consistent with those of earlier studies. Prior examinations in ambulatory specialties found that scribes increased HCC coding, ${ }^{4}$ LOS billing, ${ }^{24}$ and pay-for-performance metrics. $^{18}$ The only study to examine these areas in primary care found that scribes were associated with increased pay-for-performance measure documentation, ${ }^{20}$ a change that is necessary but insufficient to realize increased pay-forperformance revenue. Therefore, our study confirms, for the first time, that PCPs can better address pay-for-performance measures, LOS billing, and HCC coding when working with a scribe in primary care.

Demands on primary care visits are increasing. ${ }^{28}$ Physicians are required to provide more documentation; there is greater emphasis on PCPs meeting pay-for-performance measures; and there are more data in the EMR to review. In this context, addressing pay-forperformance measures and gaps in risk coding is likely to be increasingly challenging. Our study suggests that scribes might provide a mechanism to increase risk coding, LOS billing, and pay-for-performance measures, despite increased demands on primary care visits.

Increase in LOS billing. In the settings in which we work, a fee-for-service LOS 4 primary care visit generates, on average, $\$ 20$ to $\$ 75$ more in revenue than an LOS 3 visit. Using an average of $\$ 50$ additional revenue for LOS 4 billing, we estimate that a full-time scribe is associated with roughly $\$ 7,000$ in additional revenue annually. We arrived at this estimate using an average of 1500 visits at $\mathrm{LOS} \leq 3$ for every PCP full-time equivalent. A 9.2 percentage-point increase in LOS 4 billing would lead to roughly 140 additional LOS 4 visits, with each visit generating an additional $\$ 50$ in revenue.

This analysis does not account for increased revenue associated with increased pay for HCC coding identified in our study.

Furthermore, in our conservative assumption, the entire increase in LOS billing was from level 3 to level 4; in fact, a small percentage of that increase would be from level 2 and another small percentage would be to level 5-both of which would generate additional revenue. Our assumption therefore underestimates the full financial value associated with scribes in the absence of increased patient volume. Nonetheless, the assumption suggests that increases in LOS billing offset a substantial percentage of a scribe's salary.

I Limitations of this study. Our study should be interpreted in the context of several limitations:

- The study was conducted at 1 institution. Our findings might not be generalizable beyond this setting.

- The study measures the impact of scribes when providers work with scribes part time. Because providers who utilize a scribe for all, or nearly all, their visits are likely to use a scribe more efficiently, our study might underestimate the full impact of a scribe.

- In some settings, team members such as medical assistants are trained to assist with documentation and other responsibilities (such as closing care gaps) in addition to other patient care responsibilities. ${ }^{29-32}$ The extent to which our findings transfer to other models is unclear; studies comparing the impact 
of other models (which might provide even stronger outcomes) to the impact of medical scribes would be an interesting area for further research.

- In addition to the variability of models, there is likely variability in the quality and interactions of medical scribes, which might impact outcomes. We did not examine the qualities of scribes that led to outcomes in this study.

- We examined the impact of scribes on quality measure-ordering behaviors of providers, not on whether quality measures actually improved. Because scribes are associated with more faceto-face time with patients, ${ }^{27}$ they might allow for increased attention being paid by physicians to barriers to payfor-performance measures (eg, patient education). This could increase the likelihood that patients complete a multitude of screenings, and thus improve adherence and follow-up. How- ever, the impact of scribes on quality measures is a topic for future study.

I Value beyond volume. Any limitations notwithstanding, our study suggests that scribes are associated with financial benefit in addition to the benefit of increased volume. Primary care practices should therefore consider the financial benefit of scribes independent of their ability to add patient volume. By recognizing this additive value, primary care practices might more fully capture the benefit of scribes, which might then allow practices to employ scribes with less demand to increase volume. This added support without increased volume would, in turn, likely reduce provider burnout (and the costly associated turnover) and increase patient satisfaction, leading to a synergistic financial benefit.

JFP

CORRESPONDENCE

Wayne Altman, MD, FAAFP, Tufts University School of Medicine, 200 Harrison Avenue, Boston, MA 02111; wayne. altman@tufts.edu

\section{References}

1. Gellert GA, Ramirez R, Webster SL. The rise of the medical scribe industry: implications for the advancement of electronic health records. JAMA. 2015;313:1315-1316. doi: 10.1001/jama.2014.1712

2. Cho J, Sanchez K, Ganor O, et al. Utilizing a physician scribe in a pediatric plastic surgical practice: a time-driven activity-based costing study. Plast Reconstr Surg Glob Open. 2019;7:e2460. doi: 10.1097/GOX.0000000000002460

3. Danak SU, Guetterman TC, Plegue MA, et al. Influence of scribes on patient-physician communication in primary care encounters: mixed methods study. JMIR Med Inform. 2019;7:e14797. doi: $10.2196 / 14797$

4. Martel ML, Imdieke BH, Holm KM, et al. Developing a medical scribe program at an academic hospital: the Hennepin County Medical Center experience. Jt Comm J Qual Patient Saf. 2018;44:238-249. doi: 10.1016/j.jcjq.2018.01.001

5. Mishra P, Kiang JC, Grant RW. Association of medical scribes in primary care with physician workflow and patient experience. JAMA Intern Med. 2018;178:1467-1472. doi: 10.1001/ jamainternmed.2018.3956

6. Taylor KA, McQuilkin D, Hughes RG. Medical scribe impact on patient and provider experience. Mil Med. 2019;184:388-393. doi: 10.1093/milmed/usz030

7. Gidwani R, Nguyen C, Kofoed A, et al. Impact of scribes on physician satisfaction, patient satisfaction, and charting efficiency: a randomized controlled trial. Ann Fam Med. 2017;15:427-433. doi: 10.1370/afm.2122.

8. Heckman J, Mukamal KJ, Christensen A, et al. Medical scribes, provider and patient experience, and patient throughput: a trial in an academic general internal medicine practice. J Gen Intern Med. 2019;35:770-774. doi: 10.1007/s11606-019-05352-5

9. Koshy S, Feustel PJ, Hong M, et al. Scribes in an ambulatory urology practice: patient and physician satisfaction. J Urol. 2010;184:258-262. doi: 10.1016/j.juro.2010.03.040

10. McCormick BJ, Deal A, Borawski KM, et al. Implementation of medical scribes in an academic urology practice: an analysis of productivity, revenue, and satisfaction. World J Urol. 2018;36:1691-1697. doi: 10.1007/s00345-018-2293-8

11. Pozdnyakova A, Laiteerapong N, Volerman A, et al. Impact of medical scribes on physician and patient satisfaction in prima- ry care. J Gen Intern Med. Jul 2018;33:1109-1115. doi: 10.1007/ s11606-018-4434-6

12. Bank AJ, Obetz C, Konrardy A, et al. Impact of scribes on patien interaction, productivity, and revenue in a cardiology clinic: a prospective study. Clinicoecon Outcomes Res. 2013;5:399-406. doi: 10.2147/CEOR.S49010

13. Danila MI, Melnick JA, Curtis JR, et al. Use of scribes for documentation assistance in rheumatology and endocrinology clinics: impact on clinic workflow and patient and physician satisfaction. J Clin Rheumatol. 2018;24:116-121. doi: 10.1097/ RHU.0000000000000620

14. Keefe KR, Levi JR, Brook CD. The impact of medical scribes on patient satisfaction in an academic otolaryngology clinic. Ann Otol Rhinol Laryngol. 2020;129:238-244. doi: 10.1177/0003489419884337

15. Lowry C, Orr K, Embry B, et al. Primary care scribes: writing a new story for safety net clinics. BMJ Open Qual. 2017;6:e000124. doi: 10.1136/bmjoq-2017-000124

16. Rohlfing ML, Keefe KR, Komshian SR, et al. Clinical scribes and their association with patient experience in the otolaryngology clinic. Laryngoscope. 2020;130:e134-e139. doi: 10.1002/ lary. 28075

17. Arya R, Salovich DM, Ohman-Strickland P, et al. Impact of scribes on performance indicators in the emergency department Acad Emerg Med. 2010;17:490-494. doi: 10.1111/j.15532712.2010.00718x

18. Ewelukwa O, Perez R, Carter LE, et al. Incorporation of scribes into the inflammatory bowel disease clinic improves quality of care and physician productivity. Inflamm Bowel Dis. 2018;24: 552-557. doi: 10.1093/ibd/izx078

19. Misra-Hebert AD, Yan C, Rothberg MB. Physician, scribe, and patient perspectives on clinical scribes in primary care. J Gen Intern Med. 2017;32:244. doi: 10.1007/s11606-016-3888-7

20. Platt J, Altman W. Can medical scribes improve quality measure documentation? J Fam Pract. Jun 2019;68:e1-e7.

21. Guglielmo WJ. What a scribe can do for you. Med Econ. Jan 6 2006;83:42,44-46.

22. Richmond M. Don't use scribes for order entry. Emergency Medicine News. 2009;31:6-7. doi: 10.1097/01.EEM.0000360578.87654.cc

CONTINUED ON PAGE 203
Our study also suggests that scribes might provide a mechanism to increase risk coding and payfor-performance, despite increased demands on primary care visits. 


\section{CONTINUED FROM PAGE 173}

23. Schiff GD, Zucker L. Medical scribes: salvation for primary care or workaround for poor EMR usability? J Gen Intern Med. 2016;31:979-981. doi: 10.1007/s11606-016-3788-x

24. Bank AJ, Gage RM. Annual impact of scribes on physician productivity and revenue in a cardiology clinic. Clinicoecon Outcomes Res. 2015;7:489-495. doi: 10.2147/CEOR.S89329

25. Heaton HA, Castaneda-Guarderas A, Trotter ER, et al. Effect of scribes on patient throughput, revenue, and patient and provider satisfaction: a systematic review and meta-analysis. Am J Emerg Med. 2016;34:2018-2028. doi: 10.1016/j.ajem.2016.07.056

26. Earls ST, Savageau JA, Begley S, et al. Can scribes boost FPs' efficiency and job satisfaction? J Fam Pract. 2017;66:206-214.

27. Zallman L, Finnegan K, Roll D, et al. Impact of medical scribes in primary care on productivity, face-to-face time, and patient comfort. J Am Board Fam Med. 2018;31:612-619. doi: 10.3122/ jabfm.2018.04.170325

28. Abbo ED, Zhang Q, Zelder M, et al. The increasing number of clinical items addressed during the time of adult primary care visits. J Gen Intern Med. 2008;23:2058-2065. doi: 10.1007/s11606008-0805-8
29. Ammann Howard K, Helé K, Salibi N, et al. Adapting the EHR scribe model to community health centers: the experience of Shasta Community Health Center's pilot. Blue Shield of California Foundation; 2012. Accessed April 28, 2021. https:// blueshieldcafoundation.org/sites/default/files/publications/ downloadable/Shasta\%20EHR\%20Scribes\%20Final\%20Report. pdf

30. Anderson P, Halley MD. A new approach to making your doctornurse team more productive. Fam Pract Manag. 2008;15:35-40.

31. Blash L, Dower C, Chapman SA. University of Utah community clinics-medical assistant teams enhance patient-centered, physician-efficient care. Center for the Health Professions at UCSF; April 2011. Revised November 2011. Accessed April 28, 2021. https://healthforce.ucsf.edu/sites/healthforce.ucsf.edu/ files/publication-pdf/3.1\%202011_04_University_of_Utah_Community_Clinics--Medical_Assistant_Teams_Enhance_PatientCentered_Physician-Efficient\%20Care.pdf

32. Reuben DB, Knudsen J, Senelick W, et al. The effect of physician partner program on physician efficiency and patien satisfaction. JAMA Intern Med. 2014;174:1190-1193. doi: 10.1001/ jamainternmed.2014.1315 
TABLE W-1

Characteristics of scribed and nonscribed providers

\begin{tabular}{|c|c|c|c|c|c|}
\hline \multirow[t]{2}{*}{ Characteristic } & \multicolumn{2}{|c|}{$\begin{array}{l}\text { Scribed providers } \\
(n=17)\end{array}$} & \multicolumn{2}{|c|}{$\begin{array}{l}\text { Nonscribed providers } \\
(\mathrm{n}=78)\end{array}$} & \multirow[t]{2}{*}{$P$ value } \\
\hline & $\mathbf{n}$ & $\%$ & $\mathbf{n}$ & $\%$ & \\
\hline \multicolumn{5}{|l|}{ Gender } & .6376 \\
\hline Female & 11 & 64.7 & 55 & 70.5 & \\
\hline Male & 6 & 35.3 & 23 & 29.5 & \\
\hline \multicolumn{5}{|l|}{ Race } & .7889 \\
\hline Asian & 3 & 17.7 & 8 & 10.3 & \\
\hline Black or African American & 1 & 5.9 & 7 & 9.0 & \\
\hline Hispanic or Latinx & 0 & - & 1 & 1.3 & \\
\hline White & 13 & 76.5 & 62 & 79.5 & \\
\hline \multicolumn{5}{|l|}{ Type of provider } & .4911 \\
\hline Nurse practitioner & 1 & 5.9 & 9 & 11.5 & \\
\hline Physician & 16 & 94.1 & 69 & 88.5 & \\
\hline \multicolumn{5}{|l|}{ Specialty } & .7955 \\
\hline Internal medicine & 7 & 41.2 & 37 & 47.4 & \\
\hline Family medicine & 6 & 35.3 & 24 & 30.8 & \\
\hline Pediatrics & 2 & 11.8 & 11 & 14.1 & \\
\hline Geriatrics & 0 & - & 2 & 2.6 & \\
\hline Internal medicine and pediatrics & 2 & 11.8 & 4 & 5.1 & \\
\hline \multicolumn{5}{|l|}{ Outpatient clinical FTE } & .7206 \\
\hline $1 \mathrm{FTE}$ & 9 & 52.9 & 33 & 42.3 & \\
\hline 0.75 to $<1 \mathrm{FTE}$ & 5 & 29.4 & 27 & 34.6 & \\
\hline$<0.75 \mathrm{FTE}$ & 3 & 17.7 & 18 & 23.1 & \\
\hline Year that training was completed & & & & & .909 \\
\hline Mean (SD) & \multicolumn{2}{|c|}{$2002(14.3)$} & \multicolumn{2}{|c|}{$2001(11.7)$} & \\
\hline Median (range) & \multicolumn{2}{|c|}{2008 (1971-2016) } & \multicolumn{2}{|c|}{$2004(1972-2016)$} & \\
\hline \multicolumn{3}{|l|}{$\begin{array}{l}\text { Start of tenure at Cambridge Health } \\
\text { Alliance }\end{array}$} & & & .7084 \\
\hline Mean (SD) & \multicolumn{2}{|c|}{2007 (8.7) } & \multicolumn{2}{|c|}{2006 (8.2) } & \\
\hline Median (range) & \multicolumn{2}{|c|}{$2012(1994-2016)$} & \multicolumn{2}{|c|}{2007 (1983-2017) } & \\
\hline
\end{tabular}

FTE, full-time equivalent; SD, standard deviation. 